\title{
Thermoresponsive polysilsesquioxane grafted methacrylate polymer with a methoxyethylamide group
}

\author{
Mikihiro Kashio $^{1}$, Toshio Sugizaki ${ }^{1}$, Hiroyuki Takushima ${ }^{2}$, Genki Honjou ${ }^{2}$, Shin-ichi Yamamoto ${ }^{2}$ \\ and Osamu Moriya ${ }^{2}$
}

Polymer Journal (2010) 42, 190-194; doi:10.1038/pj.2009.333; published online 6 January 2010

Keywords: graft polymerization; $\mathrm{N}$-(2-Methoxyethyl)methylamine; photoiniferter; polysilsesquioxane; Thermoresponsive polymer

Recently, thermoresponsive synthetic polymers, which have shown a reversible phase separation in an aqueous solution, have attracted much attention and their applications are presented in various material scenes. ${ }^{1-6}$ A variety of investigations on thermoresponsive materials have been presented, especially, in the fields of microencapsulation, biosensors and drug delivery. ${ }^{7-17}$ Owing to the interest in such utilities we have also initiated studies on thermoresponsive organic-inorganic hybrids based on polysilsesquioxane (PSQ). The combination of PSQ with functional polymers is expected to present useful and practical hybrid materials that maintain the essential characteristics of the inorganic polysiloxane structure, such as improved mechanical strength, weatherability and heat durability. ${ }^{18-21}$ In fact, the modifications of PSQ or oligo-silsesquioxanes by grafting polymeric components have been reported by several groups. ${ }^{22-26}$ Our previous efforts, in which a polymer of $\mathrm{N}$-isopropylacrylamide (NIPAM) was chosen and introduced as the graft chain into PSQ backbone, focused on thermoresponsive properties and were also examples of modified hybrids. ${ }^{27-28}$ In the graftings from PSQ, one of the findings in the grafting of poly(NIPAM) was that at least 20 monomer units of NIPAM in a graft chain were necessary to maintain a good solubility in water. Consequently, the copolymerization of NIPAM with $\mathrm{N}, \mathrm{N}$-dimethylacrylamide was required when a small number of NIPAM monomer units in one graft chain were grafted. Consequently, copolymerization of NIPAM with $\mathrm{N}, \mathrm{N}$-dimethylacrylamide was required when a small number of NIPAM monomer units in one graft chain were grafted. This leads us to conclude that a more hydrophilic polymeric component is favorable for the efficient synthesis of thermoresponsive PSQ derivatives, which show reversible hydrophobic aggregation at the lowest critical solution temperature (LCST).

The typical structures that cause thermoresponsive property usually contain hydrophilic amide or ethylenedioxy groups with hydrophobic alkyl groups; $;^{29-33}$ therefore, we designed readily obtainable functional groups that were formed by the simple addition reaction of 2-alkoxyethylamines to the isocyanato group. The functional group, which consisted of 2-alkoxyethylamino groups and a urea bond, was introduced into PSQ as a substituent. The thermoresponsive properties of PSQ were examined in a previous report. ${ }^{34}$ On the basis of its properties, to expand applicability of the functional groups for providing the thermoresponsive property, methacrylate polymer was chosen as a versatile polymeric component in this report.

The starting monomer (MEMMA) was obtained by the reaction of commercially available 2-isocynatoethyl methacrylate (ICMA) with (2-methoxyethyl)methylamine (MEMAm). The photoiniferter technique was applied to the syntheses of thermoresponsive PSQs through graft polymerization of MEMMA, in which the PSQ with a dimethyldithiocarbamate group (DTPSQ) was used. ${ }^{27,35}$ In addition, copolymerizations of MEMMA with 2-hydroxyethyl methacrylate (HEMA) were conducted to introduce hydroxyl groups in the polymeric components. Such additional functional groups may be useful when optical and medical uses of the resulting materials are considered. ${ }^{36-38}$ The thermoresponsive behaviors of grafted PSQ derivatives were evaluated by turbidity in an aqueous solution, which was depicted as a change in optical transmittance $(\% \mathrm{~T})$.

\section{EXPERIMENTAL PROCEDURE}

Materials and characterization

${ }^{1} \mathrm{H}$ NMR and ${ }^{13} \mathrm{C}$ NMR spectra were obtained using a JEOL AL-300 and JNM A-500 spectrometer (JEOL, Tokyo, Japan) in $\mathrm{CDCl}_{3}$ or DMF- $_{7}$. IR spectra were recorded on a JASCP FT/IR 230 (JASCO, Tokyo, Japan). Gel permeation chromatographic (GPC) analysis was carried out to estimate the number-average molecular weight $\left(M_{\mathrm{n}}\right)$ and the polydispersity index $\left(M_{\mathrm{w}} / M_{\mathrm{n}}\right)$ on a Shimadzu LC-10VP chromatograph (Shimadzu, Kyoto, Japan) equipped with an evaporative light-scattering detector. Three columns, such as Shim-pack GPC80MD, $-804 \mathrm{D}$ and $-802 \mathrm{D}$ (Shimadzu), were connected in series and $\mathrm{N}, \mathrm{N}$-dimethylformamide (DMF) was used as an eluent. Calibration was based on poly(methyl methacrylate) standards. The DMF that was

${ }^{1}$ Research Laboratory, Lintec Co., Nishiki-cho, Warabi, Japan and 2Department of Applied Chemistry, National Defense Academy, Hashirimizu, Yokosuka, Japan Correspondence: Dr O Moriya, Department of Applied Chemistry, National Defense Academy, 1-10-20 Hashirimizu, Yokosuka, Kanagawa 239-8686, Japan. E-mail: moriyaos@nda.ac.jp

Received 10 July 2009; revised and accepted 13 November 2009; published online 6 January 2010 
Table 1 Graft polymerization from DTPSQ

\begin{tabular}{|c|c|c|c|c|c|c|c|}
\hline \multicolumn{4}{|c|}{ Reaction conditions ${ }^{\mathrm{a}}$} & \multicolumn{2}{|c|}{ Grafted PSQ } & \multirow[b]{2}{*}{ Calcd. $M_{n}{ }^{c}$} & \multirow[b]{2}{*}{$M_{n}^{\mathrm{d}}\left(M_{w} / M_{n}\right)$} \\
\hline & $\begin{array}{l}\text { Monomer (Feed mole ratio of monomer/Run } \\
\text { dithiocarbamate) }\end{array}$ & Product & Yieldb \% & $\begin{array}{l}\text { Yield based on } \\
\text { polymer unitb \% }\end{array}$ & $\begin{array}{l}\text { Content of monomer } \\
\text { unitc } \mathrm{mmol} \mathrm{eqg}^{-1}\end{array}$ & & \\
\hline 1 & MEMMA (10) & GrMEM1 & 94 & 86 & 3.10 & 49600 & $48800(1.48)$ \\
\hline 2 & MEMMA (20) & GrMEM2 & 90 & 76 & 3.39 & 72700 & $74600(1.44)$ \\
\hline \multirow[t]{2}{*}{3} & MEMMA (10) & GrMEMH & 75 & 81 & 1.80 & 57800 & $53600(1.21)$ \\
\hline & HEMA (10) & & & 77 & 1.69 & & \\
\hline
\end{tabular}

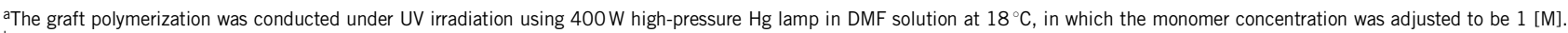
bBased on the weights of the substrates.

${ }^{c}$ Calculated from ${ }^{1} \mathrm{H}$ NMR spectral data.

dEstimated by GPC (poly(methyl methacrylate standards))

used for reactions was refluxed over calcium hydride and distilled. Tetrahydrofuran (THF) was refluxed over sodium metal before use. HEMA was distilled before use. Other reagents, including MEMAm and ICMA, were used as supplied from commercial sources. DTPSQ was prepared according to the procedure reported previously. ${ }^{27}$ The estimated values of $M_{\mathrm{n}}$ and $M_{\mathrm{w}} / M_{\mathrm{n}}$ from GPC measurements were 5300 and 1.23 , respectively. The dimethyldithiocarbamate group content in DTPSQ was $3.05 \mathrm{mmol} \mathrm{eq} \mathrm{g}^{-1}$. The measurement of transmittance $(\% \mathrm{~T})$ for thermoresponsive behavior in an aqueous solution was carried out in the same manner as described previously. ${ }^{34}$

\section{Synthesis of the methacrylate monomer}

MEMAm $(1.26 \mathrm{~g}, 14.2 \mathrm{mmol})$ was added to the solution of ICMA $(2.00 \mathrm{~g}, 12.9 \mathrm{mmol})$ in THF $(5 \mathrm{ml})$ at $0{ }^{\circ} \mathrm{C}$ in an argon atmosphere. The solution was stirred at ambient temperature for $10 \mathrm{~h}$ and, successively, evaporated under reduced pressure. The residual oil was purified by column chromatography $\left(\mathrm{SiO}_{2}\right.$, ethyl acetate) to obtain 2-methylacrylic acid 2-[3-(2-methoxyethyl)-3-methylureido]ethyl ester (MEMMA) (3.13 g, 96\%) as a colorless oil: IR (neat) 3346 (medium, NH), 2930 (weak), 1718 (strong, $-\mathrm{O}-\mathrm{C}=\mathrm{O}$ ), 1634 (strong, $-\mathrm{NH}-\mathrm{C}=\mathrm{O}$ ), 1538 (strong), 1171 (strong, $\mathrm{C}-\mathrm{O}$ ) 1118 (medium) $\mathrm{cm}^{-1} ;{ }^{1} \mathrm{H}$ NMR $\left(500 \mathrm{MHz}, \mathrm{CDCl}_{3}\right) \delta 1.86\left(\mathrm{~s}, 3 \mathrm{H},-\mathrm{CH}_{3}\right), 2.78$ (s $\left.3 \mathrm{H},-\mathrm{N}-\mathrm{CH}_{3}\right), 3.21$ (s, $\left.3 \mathrm{H},-\mathrm{O}-\mathrm{CH}_{3}\right), 3.27\left(\mathrm{~m}, 2 \mathrm{H},-\mathrm{NH}-\mathrm{CH}_{2}-\right.$ ), $3.31\left(\mathrm{t}, 2 \mathrm{H}, \bar{J}=5.0 \mathrm{~Hz},-\mathrm{N}\left(\mathrm{CH}_{3}\right)-\mathrm{CH}_{2}-\right), 3.36(\mathrm{t}, 2 \mathrm{H}, J=5.0 \mathrm{~Hz},-\mathrm{O}-$ $\left.\mathrm{CH}_{2}-\right), 4.06\left(\mathrm{t}, 2 \mathrm{H}, J=5.0 \mathrm{~Hz},-\mathrm{C}(=\mathrm{O})-\mathrm{O}-\mathrm{CH}_{2}-\right), 5.66\left(\mathrm{~s},{ }^{1} \mathrm{H}\right.$, $J=1.5 \mathrm{~Hz},=\mathrm{C}-\underline{\mathrm{H}}), 6.04\left(\mathrm{~s},{ }^{1} \mathrm{H}, J=1.2 \mathrm{~Hz},=\overline{\mathrm{C}}-\underline{\mathrm{H}}\right), 6.38\left(\mathrm{br},{ }^{1} \mathrm{H}\right.$, $-\mathrm{NH}-) ;{ }^{13} \mathrm{C} \mathrm{NMR}\left(75.45 \mathrm{MHz}, \mathrm{CDCl}_{3}\right) \delta 18.20\left(-{ }_{-} \mathrm{CH}_{3}\right), 35.07(-\mathrm{N}-$ $\left.\mathrm{CH}_{3}\right), 40.21\left(-\mathrm{NH}-\mathrm{CH}_{2}-\right), 47.69\left(-\mathrm{N}\left(\mathrm{CH}_{3}\right)-\mathrm{CH}_{2}-\right), 58.26\left(-\mathrm{O}-\mathrm{CH}_{3}\right)$, $63.80\left(-\mathrm{C}(=\mathrm{O})-\mathrm{O}-\overline{\mathrm{C}} \mathrm{H}_{2}-\right), 70.67\left(-\mathrm{O}-\mathrm{CH}_{2}-\overline{)}\right), 125.94\left(\mathrm{CH}_{2}=\right), \overline{13} 6.14$ $\left(=\mathrm{C}-\mathrm{CH}_{3}\right), 157.89(-\mathrm{N}-\mathrm{C}=\mathrm{O}), 166.79(-\mathrm{C}(=\mathrm{O})-\mathrm{O}-)$. Anal. Calcd for $\mathrm{C}_{11} \overline{\mathrm{H}}_{20} \mathrm{~N}_{2} \mathrm{O}_{4}$ : C, 54.08, $\overline{\mathrm{H}}, 8.25, \mathrm{~N}, 11.47$. Found: C, $54.28, \mathrm{H}, 8.34, \mathrm{~N}$, 11.58. The underlined elements indicate objective elements for NMR.

\section{Typical procedure for grafting of the methacrylate polymer from DTPSQ}

A solution of DTPSQ $(0.05 \mathrm{~g}, 0.14 \mathrm{mmol}$ eq of the dithiocarbamate group) and MEMMA $(0.40 \mathrm{~g}, 1.45 \mathrm{mmol})$ in DMF $(1.5 \mathrm{ml})$ was introduced into a glass tube. The solution was purged of air by means of three vacuum-argon cycles. Then, the mixture in the glass tube was irradiated at $18^{\circ} \mathrm{C}$ using a RIKO RH400 UV lamp (RIKO, Taipei, Taiwan), equipped with a water jacket, from a distance of $10 \mathrm{~cm}$ for $20 \mathrm{~h}$ in an argon atmosphere. The resulting solution was evaporated under reduced pressure, as a concentration step, and the residue was poured into diethyl ether. Insoluble wax was collected and dissolved in acetone. The solution was poured into an excess amount of diethyl ether to precipitate the product. After drying at room temperature for $24 \mathrm{~h}$ under reduced pressure $(<5 \mathrm{~mm} \mathrm{Hg})$, the grafted product (GrMEM1, $0.41 \mathrm{~g}, 94 \%$ by weight, Table 1, Run1) was obtained: IR ( $\mathrm{KBr}) 3340$ (medium, NH), 2950 (weak), 1718 (strong, $-\mathrm{O}-\mathrm{C}=\mathrm{O}$ ), 1636 (strong, $-\mathrm{NH}-\mathrm{C}=\mathrm{O}$ ), 1539 (strong), 1175 (strong, $\mathrm{C}-\mathrm{O}), 1116$ (medium) $\mathrm{cm}^{-1}$; ${ }^{1} \mathrm{H}$ NMR $\left(300 \mathrm{MHz}, \mathrm{CDCl}_{3}\right) \delta 0.81$ (br, $-\mathrm{CH}_{3}$ ), 0.99 (br, $-\mathrm{CH}_{3}$ ), 1.79 (br, $-\mathrm{CH}_{2}-$ ), 2.88 (br, -N-CH$), 3.30$ (br $\left.\mathrm{m},-\mathrm{OCH}_{3}\right), 3.37-\overline{3.44}$ (br m, $-\mathrm{NH}-\mathrm{CH}_{2}-,-\mathrm{N}\left(\mathrm{CH}_{3}\right)-\overline{\mathrm{CH}}_{2}-,-\mathrm{O}-$ $\mathrm{CH}_{2}-$ ), 3.95 (br, $-\mathrm{C}(=\mathrm{O})-\mathrm{O}-\mathrm{CH}_{2}-$ ), 5.72 (br, $\left.-\mathrm{NH}-\right), 7 . \overline{4}-7.18$ (br $\left.\mathrm{m},-\mathrm{C}_{6} \mathrm{H}_{4}-\right) ;{ }^{13} \mathrm{C} \mathrm{NMR}\left(75.45 \overline{\mathrm{MHz}}, \mathrm{CDCl}_{3}\right) \delta 17.24\left(-\mathrm{CH}_{3}\right), 31.50$ $\left(-\mathrm{CH}_{2}-\right), 35.17\left(-\mathrm{N}-\mathrm{CH}_{3}\right), 39.37\left(-\mathrm{NH}-\mathrm{CH}_{2}-\right), 44.75$ (- $\left.\overline{\mathrm{C}}(=\mathrm{O})-\mathrm{C}-\right)$, $49.11 \quad\left(-\mathrm{N}\left(\mathrm{CH}_{3}\right)-\mathrm{CH}_{2}-\right), \quad 58.97 \quad\left(-\mathrm{O} \overline{\mathrm{C}} \mathrm{H}_{3}\right), \quad 64.40 \quad(-\mathrm{C}(=\mathrm{O})-\mathrm{O}-$ $\left.\mathrm{CH}_{2}-\right), 71.58\left(-\mathrm{O}-{ }_{-} H_{2}-\right), 158.81(-\mathrm{NH}-\mathrm{C}=\mathrm{O}), 177.17(-\underline{\mathrm{C}}(=\mathrm{O})-$ O-).

The amounts of the N,N-dimethyldithiocarbamate group and the monomer units in GrMEM1 were calculated from the peak areas observed in the ${ }^{1} \mathrm{H}$ NMR spectrum, in which hexamethyldisiloxane was used as an internal standard. The signals due to the dimethyldithiocarbamate group could not be detected clearly, so its content was estimated from the signals of the phenyl group instead.

Analogously, grafted PSQs were prepared under the conditions listed in Table 1. The spectral data for grafting the copolymer of MEMMA with HEMA (GrMEMH) were as follows: IR (neat) 3365 (medium, NH), 3320 (medium, OH), 2932 (weak), 1718 (strong, -O$\mathrm{C}=\mathrm{O}$ ), 1632 (strong, $-\mathrm{NH}-\mathrm{C}=\mathrm{O}$ ), 1540 (strong), 1172 (strong, $\mathrm{C}-\mathrm{O}$ ), 1117 (medium) $\mathrm{cm}^{-1} ;{ }^{1} \mathrm{H}$ NMR $\left(300 \mathrm{MHz}, \mathrm{CDCl}_{3}\right) \delta 0.87-1.01$ (br $\mathrm{m},-\mathrm{CH}_{3}$ ), 1.78-2.06 (br m, $-\mathrm{CH}_{2}-$ ), 2.90 (br, $-\mathrm{N}-\mathrm{CH}_{3}$ ), 3.33-3.49 (br m, $-\mathrm{O}-\mathrm{CH}_{3},-\mathrm{N}-\mathrm{CH}_{2}-,-\mathrm{NH}-\mathrm{CH}_{2}-,-\mathrm{O}-\mathrm{CH}_{2}-,-\mathrm{CH}_{2}-\mathrm{OH}$ ), 3.78 (br, $\left.-\mathrm{C}(=\mathrm{O})-\mathrm{O}-\overline{\mathrm{CH}}_{2}-\mathrm{CH}_{2} \mathrm{OH}\right), 4.00\left(\mathrm{br},-\overline{\mathrm{C}}(=\mathrm{O})-{ }_{-}-\mathrm{CH}_{2}-\right)$, 5.70 (br, $-\mathrm{NH}-$ ), 7.05-7.07 (br m, $\left.-\mathrm{C}_{6} \mathrm{H}_{4}-\right) ;{ }^{13} \mathrm{C} \mathrm{NMR}(75.45 \overline{\mathrm{MHz}}$, $\left.\mathrm{CDCl}_{3}\right) \delta 18.26\left(-\mathrm{CH}_{3}\right), 39.67\left(-\mathrm{N}-\overline{\mathrm{CH}}_{2}-\right), 49.00\left(-\mathrm{NH}-\mathrm{CH}_{2}-\right)$, $58.91\left(-\mathrm{O}-\mathrm{CH}_{3}\right), \overline{64} .44\left(-\mathrm{C}(=\mathrm{O})-\mathrm{O}-\mathrm{CH}_{2}-\right), 72.71\left(-\mathrm{O}-\overline{\mathrm{C}} \mathrm{H}_{2}-\right)$, $125.52\left(\underline{\mathrm{CH}_{2}}=\right), \quad 136.24 \quad\left(=\underline{\mathrm{C}}-\mathrm{CH}_{3}\right), \quad \overline{1} 59.50 \quad(-\mathrm{N}-\underline{\mathrm{C}}=\mathrm{O}), \quad 167.31$ $(-\underline{\mathrm{C}}(=\mathrm{O})-\mathrm{O}-)$.

\section{RESULTS AND DISCUSSION}

\section{Polymerization of the methacrylate polymer}

In a previous report, several alkoxyethylamide groups, introduced as the substituent of the PSQ backbone, were shown to be effective for providing amphiphilic and thermoresponsive properties. ${ }^{34}$ Analogously, in preliminary experiments, several methacrylate monomers with alkoxyethylamide groups were prepared. For example, the monomers that had a bis(2-methoxyethyl)amide group yielded the corresponding thermoresponsive polymer. The obtained polymer displayed hydrophobic aggregation at $20^{\circ} \mathrm{C}$ in an aqueous solution. A polymer that aggregated near human body temperature $\left(36^{\circ} \mathrm{C}\right)$ is preferable for an accurate measurement of thermoresponsive behavior and in consideration of medical usages. Consequently, MEMAm, which proved to be more hydrophilic in the previous study, ${ }^{34}$ was chosen here. 
The additional reaction of MEMAm to the isocyanato group in ICMA was conducted at ambient temperature to afford the methacrylate monomer, MEMMA, in 96\% yield. Spectral data and elemental analysis supported the formation of the desired monomer. The graft polymerizations of MEMMA from DTPSQ, which contained the analogous structure to benzyl diethyldithiocarbamate, were carried out by way of the photoiniferter technique under UV irradiation, using a $400 \mathrm{~W}$ high-pressure mercury lamp at $18^{\circ} \mathrm{C}$ in DMF solution. Products were isolated as an insoluble solid from diethyl ether. The results of polymerizations are listed in Table 1 . In cases in which 10 and 20 eq of MEMMA were added to the initiator specie, the grafted PSQs, GrMEM1 and GrMEM2, were obtained in 94 and $90 \%$ by weight yield, respectively (Table 1 , Run 1 and 2 ). The numberaveraged molecular weights estimated by GPC were 48800 for GrMEM1 and 74600 for GrMEM2. The increase in experimental $M_{\mathrm{n}} \mathrm{s}$ reflected the feed molar ratios and was reasonable in comparison with those by ${ }^{1} \mathrm{H}$ NMR spectral data. In a similar manner, the grafting of the copolymer of MEMMA and HEMA resulted in the corresponding grafted product, GrMEMHE, in $75 \%$ yield based on the weights of substrates (Table 1, Run 3). However, a subset of the initiator groups on DTPSQ seemed to be ineffective for the graftings. In the



Figure 1 GPC chromatograms of DTPSQ and GrMEM1. preliminary experiment, polymerization was conducted with benzyl diethyldithiocarbamate (BDTC) as an initiator under analogous conditions. From the polymerization, in which the feed molar ratio of MEMMA to BDTC was adjusted to 30 , methacrylate polymer was obtained in $68 \%$ yield and the $M_{\mathrm{n}}$ estimated by GPC was 12300 . The calculated $M_{\mathrm{n}}$ from the peak areas of benzene protons owing to BDTC and the monomer unit in ${ }^{1} \mathrm{H}$ NMR spectrum was 12600 . The values were in good agreement; however, they were larger than the theoretical $M_{\mathrm{n}}$ of 7600 , which was estimated from the feed molar ratio of the monomer to BDTC. Consequently, results may indicate that BDTC insufficiently contributes to photoiniferter polymerization. The GPC chromatograms of the grafted PSQs showed a unimodal peak. The GPC chromatograms of DTPSQ and GrMEM1 are shown in Figure 1.

The introduction of polymeric components was supported by spectral data. In the ${ }^{1} \mathrm{H}$ NMR spectrum of GrMEMs, the signal assigned to the protons of the methylene group that bonded to the nitrogen of the dimethyldithiocarbamate group was scarcely detected. Consequently, the peak area of the benzene ring, observed around 7 p.p.m., was used for the calculation of the content of the initiator species. The content of the methacrylate monomer unit could be estimated by the areas of the signal due to methylene protons bonded to the ester group or that, owing to methyl protons bonded to nitrogen, which appeared at 3.95 p.p.m. and 2.90 p.p.m., respectively. In the case of the copolymer obtained from MEMMA and HEMA, the signal of methylene protons that bonded to the ester group in the HEMA unit was observed at 3.78 p.p.m., as shown in Figure 2. The peak areas of these could be used for the calculation of the contents of monomer units. The ${ }^{13} \mathrm{C}$ NMR spectra also demonstrated the presence of monomer units. The signal due to the carbonyl carbon of the ester group was observed at 177.17 p.p.m. and the signal at 158.81 p.p.m. was assigned to the carbonyl carbon of the urea bond. Furthermore, in the IR spectra of polymers, the strong absorbance at approximately $1720 \mathrm{~cm}^{-1}$ demonstrated the presence of the carbonyl group of the ester bond. Absorbance due to the carbonyl group of the urea bond was observed at $1636 \mathrm{~cm}^{-1}$. Thus, graft polymerization of the methacrylate monomers from DTPSQ could be performed using the photoiniferter technique. The synthetic route mentioned above

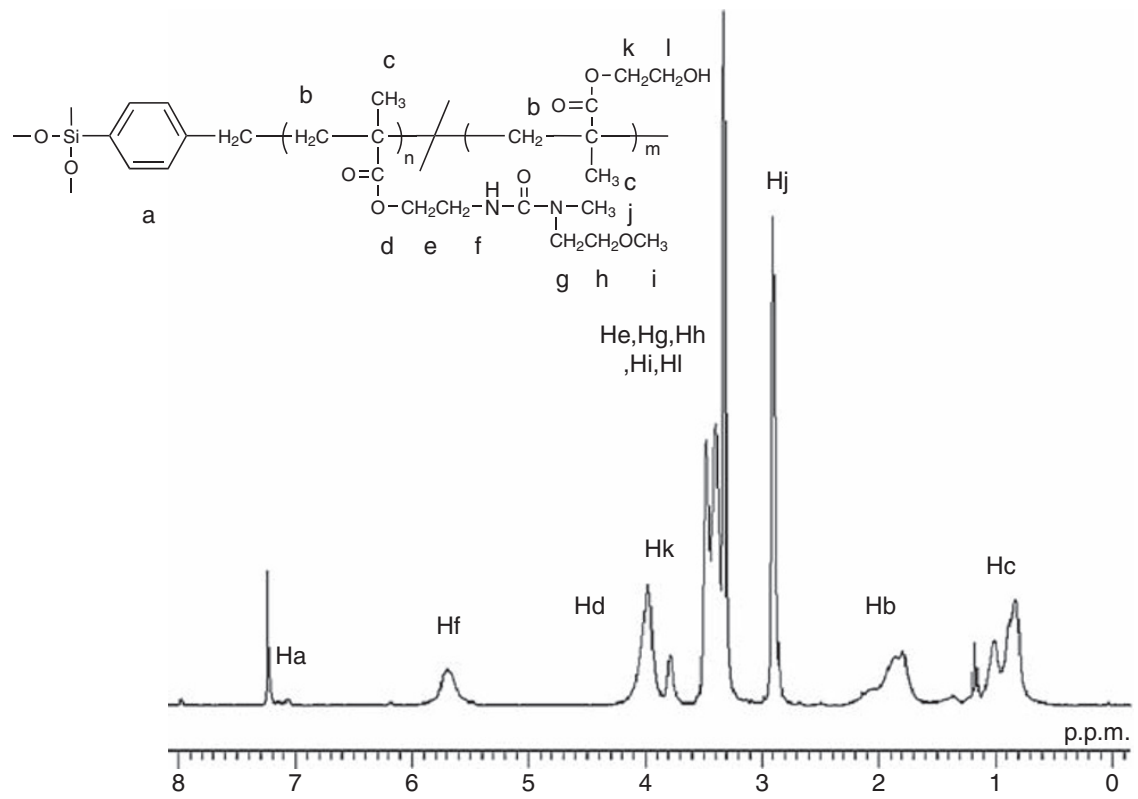

Figure $2{ }^{1} \mathrm{H}$ NMR spectrum of GrMEMHE. 

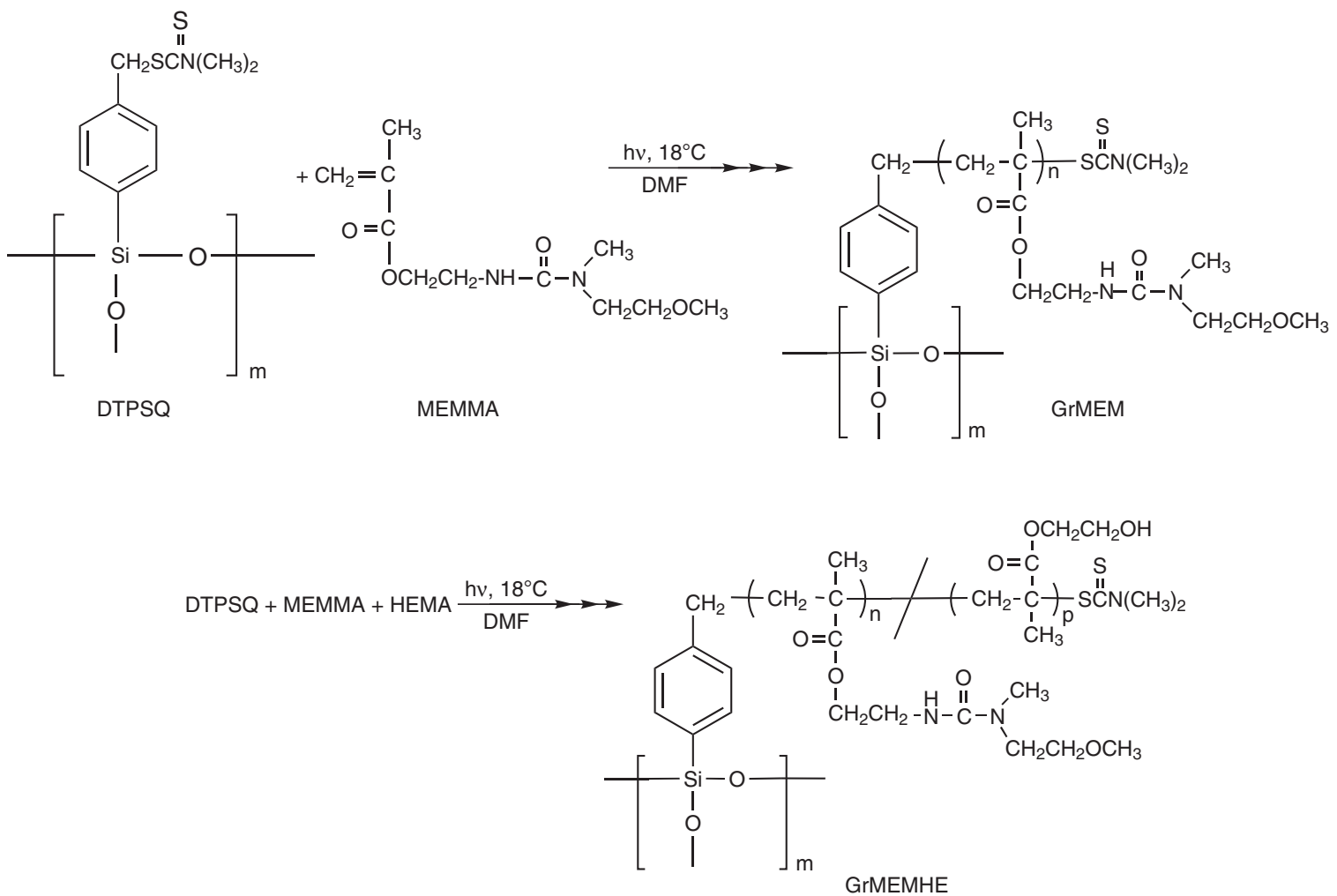

Scheme 1

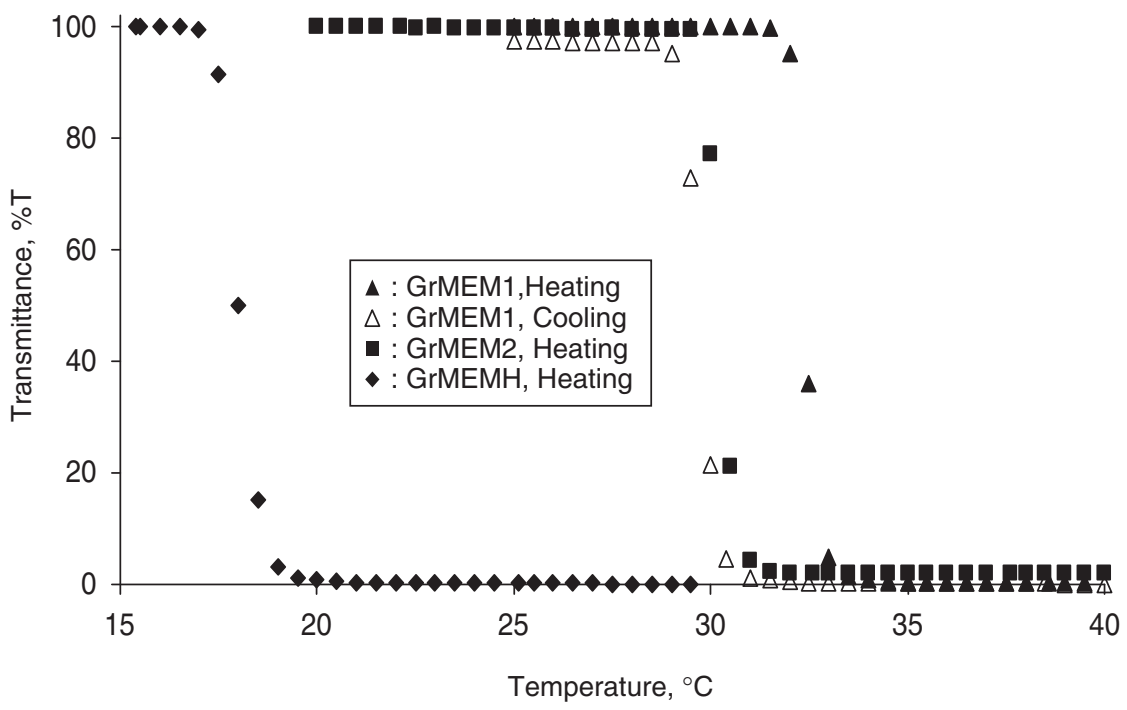

Figure 3 Temperature dependence of the optical transmittance $(\% \mathrm{~T})$ at $800 \mathrm{~nm}$ for a 1 wt\% aqueous solution of grafted PSQ under heating and cooling $\left(1^{\circ} \mathrm{C}\right.$ per $\left.\mathrm{min}\right)$.

was shown in Scheme 1. However, the depicted structure of the polysiloxane unit may be different from the actual form. In the IR spectrum of DTPSQ, a weak absorption due to the hydroxyl group was observed. ${ }^{27}$ In our previous investigation on the formation of PSQ with phenyl groups under similar basic conditions, the ${ }^{29}$ Si NMR spectrum showed the signals assigned to both the $\mathrm{T}^{2}$ and $\mathrm{T}^{3}$ structures. ${ }^{39}$ Therefore, the structure of the polysiloxane main chain of DTPSQ was thought to consist of incomplete ladder and cage structures, but not to be randomly cross-linked.

\section{Thermoresponsive behavior of the methacrylate polymer}

The thermoresponsive phase separations of the obtained methacrylate polymers were evaluated by turbidity, which was indicated as $\% \mathrm{~T}$ at $800 \mathrm{~nm}$. The thermoresponsive behaviors of grafted PSQs are shown in Figure 3. Even in the case of GrMEM1, which introduced approximately 10 monomer units in a graft chain, the hydrophobic aggregation could be observed clearly. In the behavior of GrMEM1, an LCST of $32{ }^{\circ} \mathrm{C}$ was recorded. The effects of molecular weight of the graft chain appeared in the case of GrMEM2, which was designed to 
contain a double numerical unit of the monomer. In the aqueous solution of GrMEM2, the aggregation started at $30^{\circ} \mathrm{C}$. In addition, GrMEMHE, containing the copolymer of MEMMA with HEMA, showed an LCST of $17^{\circ} \mathrm{C}$. Results demonstrated that the introduction of methacrylate polymers by grafting successfully provided the expected thermoresponsive property to PSQ. In addition, the response of hydrophobic aggregation to temperature, in which the change of transmittance from 100 to $0 \% \mathrm{~T}$ was completed within ca. $2.5^{\circ} \mathrm{C}$, was one of the favorable aspects for the use of the methacrylate polymer as the graft chain of PSQ. In the previous study concerning PSQ with a poly(NIPAM) graft chain, it took almost $5{ }^{\circ} \mathrm{C}$ for the accomplishment of the transmittance change. ${ }^{28}$ In the case of the PSQ containing the analogous low-molecular-weight alkoxyethylamide group, the change required the temperature range of ca. $4{ }^{\circ} \mathrm{C} .{ }^{34}$ Such a good response seems to be brought about by an appropriate balance of hydrophilic and hydrophobic properties of the methacrylate graft polymer.

In the preliminary experiment, the methacrylate polymer, the molar ratio of which to the initiator was adjusted to be 30 , was prepared by BDTC under conditioning similar to those mentioned above. In the case of the methacrylate polymer, the hydrophobic aggregation started at $45.5^{\circ} \mathrm{C}$ and completed at ca. $47.5^{\circ} \mathrm{C}$ under heating. In the aggregation of another polymer, which was prepared by free radical photopolymerization in the presence of a catalytic amount of $N, N^{\prime}$ azobisisobutyronitrile and showed a larger $M_{\mathrm{n}}$ such as 21600 with a dispersity of 2.34, the aggregation occurred at a slightly lower temperature of $43^{\circ} \mathrm{C}$. The grafted PSQs showed lower LCSTs compared with those of the methacrylate polymers. Such data suggested that the presence of the PSQ main chain containing benzyl groups contributed to the creation of a hydrophobic environment.

\section{CONCLUSIONS}

The methacrylate monomer with the $N$-(2-methoxyethyl)methylamino group and the urea bond, MEMMA, was found to afford a new thermoresponsive polymer. The monomer was used for graft polymerization from PSQ to provide thermoresponsive property. Results demonstrated that effective graft polymerizations proceeded without the formation of a cross-linked product and the methacrylate polymers containing different numbers of monomer units were successfully introduced onto the PSQ backbone. Such grafted derivatives of PSQ possessed the expected amphiphilic and thermoresponsive property. The use of the methacrylate polymer as the graft chain to prepare a multifunctional PSQ hybrid is still under investigation now and will be presented in the near future, in which the information mentioned above should be helpful.

1 Djokpe, E. \& Vogt, W. $\mathrm{N}$-isopropylacrylamide and $\mathrm{N}$-isopropylmethacryl-amide: cloud points of mixture and copolymers. Mcromol. Chem. Phys. 202, 750-757 (2001).

2 Gil, E. S. \& Hudson, S. M. Stimuli responsive polymers and their conjugates. Prog. Polym. Sci. 29, 1173-1122 (2004).

3 Masci, G., Giacomelli, L. \& Crescenzi, V. Atom transfer radical polymerization of $\mathrm{N}$-Isopropylacrylamide. Macromol. Rapid. Commu. 25, 559-564 (2004).

4 Sugihara, S., Kanaoka, S. \& Aoshima, S. Double thermosensitive diblock copolymers of vinyl ethers with pendant oxyethylene groups: unique physical gelation. Macromolecules 38, 1919-1927 (2005).

5 Uguzdogan, E. T., Camli, O. S., Kabasaki, S., Patir, E., Ozturk, E., Denkbas, B. \& Tuncel, A. A new temperature-sensitive polymer: poly(ethoxypropylacrylamide). Eur. Polym. J. 41, 2142 (2005).

6 Skrabania, K., Kristen, J., Laschewsky, A., Akdemir, O., Hoth, A. \& Lutz, J.- F. Design, synthesis, and aqueous aggregation behavior of nonionic single and multiple thermoresponsive polymers. Langmuir 23, 84-93 (2007).

7 Kikuchi, A. \& Okano, T. Pulsatile drug release control using hydrogels. Adv. Drug. Deliver. Rev. 54, 53-77 (2002).
8 Peppas, N. A., Bures, P., Leobandung, W. \& Ichikawa, H. Hydrogels in pharmaceutical formulations. Eur. J. Pharm. Biopharm. 50, 27 (2000).

9 Stile, R. A. \& Healy, K. E. Thermo-reversible peptide-modified hydrogels for tissue regeneration. Biomacromolecules 2, 185-194 (2001).

10 Haraguchi, K., Takehisa, T. \& Ebato, M. Control of cell cultivation and cell sheet detachment on the surface of polymer/clay nanocomposite hydrogels. Biomacromolecules 7, 3267-3275 (2006).

11 Tessmar, J. K. \& Goepferich, A. M. Customized PEG-derived copolymers for tissueengineering applications. Macromol. Biosci. 7, 23-39 (2007).

12 Lei, M., Gu, Y., Baldi, A., Siegel, R. A. \& Ziaie, B. A high resolution technique for fabricating environmentally sensitive hydrogel structures. Langmuir 20, 8947-8951 (2004).

13 Ohashi, H., Hiraoka, Y., Nakao, S. \& Yamaguchi, T. An autonomous phase transitioncomplexation/decomplexation polymer system with a molecular recognition property. Macromolecules 39, 2614-2620 (2006).

14 Heskins, M. \& Guillet, J. E. Solution properties of Poly(N-isopropylacrylamide). J. Macromol. Sci. Chem. A2, 1441-1455 (1968).

15 Chen, G. H. \& Hoffman, A. S. Graft copolymers that exhibit temperature-induced phase transitions over a wide range of $\mathrm{pH}$. Nature 373, 49-52 (1995).

16 Meyer, S. \& Richtering, W. Influence of polymerization conditions on the structure of temperature sensitive poly( $\mathrm{N}$-iso-propylacrylamid) (PNiPAM) microgels. Macromolecules 38, 1517-1519 (2005).

$17 \mathrm{Kim}, \mathrm{K}$. S. \& Vincent, B. pH and Temperature-sensitive Behaviors of Poly(4-vinyl pyridine-co- $N$-isopropyl acrylamide) Microgels. Polym. J. 37, 565-570 (2005).

18 Baney, R. H., Cao, X., Johns, R. G., Ando, W. \& Chojnowski, J. (eds). In SiliconContaining Polymers, Kluwer: Dordrecht, 2000.

19 Roy, D. A. \& Shea, K. J. Bridged polysilsesquioxanes. Highly porous hybrid organicinorganic materials. Chem. Rev. 95, 1409-1442 (1995).

20 Kondo, T., Yoshi, K., Horie, K. \& Itoh, M. Photoprove Study of Siloxane Polymers. 3. Local Free Volume of polymethylsilsesquioxane Proved by Photoisomerization of Azobenzene. Macromolecules 33, 3650 (2000).

21 Krishnan, P. S. G. \& He, C. Synthesis, characterization, and polymerization kinetics of novel ladder-like polysilsesquioxanes containing side-chain propyl methacrylate groups. Macromol. Chem. Phys. 204, 531-539 (2003).

22 Pyun, J. \& Matyjaszewski, K. Synthesis of nanocomposite organic/inorganic hybrid materials using controlled/'Living' radical polymerization. Chem. Mater. 13, 3436-3438 (2001).

$23 \mathrm{Kim}$, K- M., Keum, D- K. \& Chujo, Y. Organicinorganic polymer hybrids using polyoxazoline initiated by functionalized silsesquioxane. Macromolecules 36, 867-875 (2003).

24 Suzuki, K., Oku, J., Takai, M., Okabayashi, H. \& O'Connor, C. J. Synthesis and condensation of 3-(Triethoxysilyl)propyl-terminated polystyrene. Polym. J. 35, 938-944 (2003).

25 Cardoen, G. \& Coughlin, E. B. Hemi-Telechelic polystyrene-POSS copolymers as model systems for the study of well-defined inorganic/organic hybrid materials. Macromolecules 37, 5123-5126 (2004).

26 Fu, B. X., Lee, A. \& Haddad, T. S. Styrenebutadienestyrene triblock copolymers modified with polyhedral oligomeric silsesquioxanes. Macromolecules 37, 5211-5218 (2004).

27 Masuda, T., Yamamoto, S., Moriya, O., Kashio, M. \& Sugizaki, T. Preparation of stimuliresponsive polysilsesquioxane grafted block copolymer of acrylamide monomers. Polym. J. 40, 126-136 (2008).

28 Moriya, O., Yamamoto, S., Masuda, T., Kashio, M. \& Sugizaki, T. Preparation of thermoresponsive grafted polysilsesquioxane from polyacrylamides having methoxysilyl end group. Polym. J. 40, 1042-1048 (2008).

29 Wohlrab, S. \& Kuckling, D. İultisensitive polymers based on 2-vinylpyridine and $\mathrm{N}$ isopropylacrylamide. J. Polym. Sci., Part A: Polym. Chem. 39, 3797-3804 (2001).

30 Skrabania, K., Kristen, J., Laschewsky, A., Akdemir, Õ., Hoth, A. \& Lutz, J.- F. Design, synthesis, and aqueous aggregation behavior of nonionic single and multiple thermoresponsive polymers. Langmuir 23, 84-93 (2007).

31 Park, J. S., Akiyama, Y., Winnik, F. M. \& Kataoka, K. Versatile synthesis of [32] endfunctionalized thermosensitive poly(2-isopropyl-2-oxazolines). Macromolecules 37, 6786-6792 (2004).

32 Iwasaki, Y., Wachiralarpphaithoon, C. \& Akiyoshi, K. Novel thermoresponsive polymers having biodegradable phosphoester backbones. Macromolecules 40, 8136-8138 (2007).

33 Seno, K., Kanaoka, S. \& Aoshima, S. Thermosensitive diblock copolymers with designed molecular weight distribution: synthesis by continuous living cationic polymerization and micellization behavior. J. Polym. Sci., Polym. Chem. 46, 2212-2221 (2008).

34 Matsuoka, T., Yamamoto, S. \& Moriya, O. A new amphiphilic and thermoresponsive polysilsesquioxane having alkoxyethylamide group. Chem. Lett. 37, 772-773 (2008).

35 Otsu, T. Iniferter concept and living radical polymerization. J. Polym. Sci., Polym. Chem. 38, 2121-2136 (2000).

36 Çiçek, H. \& Tuncel, A. Immobilization of $\alpha$-chymotrypsin in thermally reversible isopropylacrylamide-hydroxyethylmethacrylate copolymer gel. J. Polym. Sci., Polym. Chem. 36, 543-552 (1998).

37 Abraham, S., Brahim, S., Ishikawa, K. \& Guiseppi-Elie, A. Molecularly engineered $\mathrm{P}(\mathrm{HEMA})$-based hydrogels for implant biochip biocompatibility. Biomaterials 26, 4767-4778 (2005)

38 Weaver, J. V. M., Bannister, I., Robinson, K. L., Bories-Azeau, X., Armes, S. P., Smallridge, M. \& Mckenna, P. Stimulus-responsive water-soluble polymers based on 2-hydroxyethyl methacrylate. Macromolecules 37, 2395-2403 (2004).

39 Matsubara, Y., Konishi, W., Sugizaki, T. \& Moriya, O. Synthesis of poly(phenylsilsesquioxane) having organostannyl groups. J. Polym. Sci., Part A: Polym. Chem. 39, 2125-2133 (2001). 